\title{
O-Phenylenediamine-Cysteine Nanosphere Having Conjugated Structures: A Highly Selective Fluorescent Probe for Mercury Ion
}

\author{
Liping Duan ${ }^{1}$, Xun Song ${ }^{1}$, Huaiyu Sun², Siwei Yang ${ }^{3}$ and Fang Liao* \\ ${ }^{1}$ Chemical Synthesis and Pollution Control, Key Laboratory of Sichuan Province, School of Chemistry and \\ Chemical Industry, China West Normal University, Nanchong,637002,China. \\ ${ }^{2}$ Applied Technique College of Southwest Petroleum University,Nanchong, 637002, China. \\ ${ }^{3}$ State Key Laboratory of Functional Materials for Informatics, Shanghai Institute of Microsystem and Information \\ Technology, Shanghai, 20050, China \\ Email: liaozhang2003@163.com
}

\begin{abstract}
A sensitive fluorescent o-phenylenediamine-cysteine copolymer dots (O-Cys) detection system for $\mathrm{Hg}^{2+}$ was synthesized by a facile and one step hydrothermal method. As a sensitive fluorescent probe, the O-Cys showed excellent linear relationships with detection limit as low as $1.0 \times 10^{-11} \mathrm{M}$ with the concentrations of $\mathrm{Hg}^{2+}$ increasing from $2 \times 10^{-11} \mathrm{M}$ to $9 \times 10^{-11} \mathrm{M}$. What's more, the O-Cys for the detection of $\mathrm{Hg}^{2+}$ was superior to most current methods and fluorescent material. At the same time, the working mechanism of $\mathrm{O}-\mathrm{Cys}$ for $\mathrm{Hg}^{2+}$ detection was also explored. $\mathrm{Hg}^{2+}$ had higher fluorescent quenching ability for as-prepared O-Cys because $\mathrm{Hg}^{2+}$ was interation with amino group ($\mathrm{NH}_{2}$ ) and thiol group (-SH) via a series of contrast test. And - $\mathrm{SH}$ enhanced the ability of $\mathrm{Hg}^{2+}$ detection to some extent. Therefore, this paper provided a good exponent of detection $\mathrm{Hg}^{2+}$ with low detection limit.
\end{abstract}

Keywords: o-phenylenediamine-cysteine, nanosphere, $\mathrm{Hg}^{2+}$ detection, fluorescent probe.

\section{Introduction}

Environmental contamination and human live in an environment full of heavy metal ions (such as $\mathrm{Cu}^{2+}$, $\mathrm{Cd}^{2+}, \mathrm{Ni}^{2+}, \mathrm{Ag}^{+}, \mathrm{Hg}^{2+}$ and $\mathrm{Pb}^{2+}$ ), which arising from a variety of natural processes and human activities, have been a critical issue of concern throughout the world for decades[1-5]. As an example of highly toxic and widespread pollutants, the water-soluble mercury(II) $\left(\mathrm{Hg}^{2+}\right)$, one of the most usual and stable forms of mercury pollution, can damage the brain, nervous system, kidneys, and endocrine system[6, 7]. It is estimated by US Environmental Protection Agency (EPA), the annual total global mercury emissions from all sources, both natural and human-generated, reaches nearly 7500 tons per year. The maximum level of mercury in drinking water permitted by the World Health Organization (WHO) and the U.S. EPA is 30 and $10 \mathrm{nM}$, respectively $[7,10,11]$. Therefore, it is especially important for studying new method with high sensitivity and selectivity to detect the trace amounts of $\mathrm{Hg}^{2+}$ in water [8, 9]. Various methods for detecting $\mathrm{Hg}^{2+}$ from nature water and industrial waste have been extensively used, including photoelectrochemical method, atomic absorption spectroscopy (AAS), coupled plasma mass spectrometry (ICP-MS), surface enhanced Raman scattering (SERS), fluorescence spectrophotometer, electro-deposition [12-14]. Among these, fluorescence spectrophotometer is one of the most attractive methods because of its simplicity, low-cost and ectiveness for water treatment. Feng et al. reported a cyclometallated ruthenium complex-modified upconversion nanophosphors for detection of $\mathrm{Hg}^{2+}$ ions in water with the detection limit of $8.2 \mathrm{ppb}$ [15]. Liu et al. reported a novel ratiometric fluorescent chemodosimeter for reusable detection of $\mathrm{Hg}^{2+}$ with the detection limit of 1.0ppb [16].

A amount of studies about the development and application of fluorescent material, such as semiconductor quantum dots, fluorescent dyes, carbon quantum dots and graphene quantum dots, have been explored to detect heavy metal ions [17-20]. Semiconducting polymer quantum dots (Pdots) have emerged as a new class of promising fluorescent nanomaterials with high emission rates, extraordinary fluorescence brightness, excellent photostability, high quantum yields, large absorption cross-sections. [21-26]. Compared with ordinary fluorescent material, the Pdots are prepared easily, low cost, low 
cytotoxicity, lack of heavy metal ions. These superior properties make them well-suited for widespread fields such as biological detection and imaging, various biosensing platforms and so on [23, 27-29]. Chiu et al. reported various Pdots with controllable PL properties and applied them to cellular imaging and heavy metal ions analysis[30-32].

The thiol group (-SH) is an excellent ligand because of its strong binding ability for various heavy metal ions, such as $\mathrm{Hg}^{2+}, \mathrm{Pd}^{2+}, \mathrm{Mn}^{2+}$ and $\mathrm{Fe}^{3+}$ [33-35]. The low-molecular-weight thiols, such as L-cysteine (L-Cys), homocysteine (Hcy), and glutathione (GSH), which play important roles in many physiological and biochemical application [36]. L-Cys molecule contains a -SH which makes it unique among the amino acids [37]. So we want to synthesize a material containing - SH for detection of metal ions based on above reasons. Though they have been widely researched, it is still a challage to develop new materials with conjugated structures, which are applied in detection of heavy metal ions.

Herein, o-phenylenediamine-cysteine copolymer dots (O-Cys) was successfully fabricated via a simple hydrothermal approach. This O-Cys showed high fluorescence response for detection of $\mathrm{Hg}^{2+}$. As the concentrations of $\mathrm{Hg}^{2+}$ were increased from $2 \times 10^{-11} \mathrm{M}$ to $9 \times 10^{-11} \mathrm{M}$, O-Cys showed excellent linear relationships and the detection limits was $1.0 \times 10^{-11} \mathrm{M}$. What's more, it showed high selectivity for $\mathrm{Hg}^{2+}$ among most of anion and cation, so it could be as a sensitive fluorescence probe for detection of $\mathrm{Hg}^{2+}$ ion. In addition, we also explored further the working mechanism of $\mathrm{Hg}^{2+}$ detection. A schematic diagram of the mechanism of O-Cys for $\mathrm{Hg}^{2+}$ detection was shown in Scheme 1. Condensation reaction generated between the two amine groups of o-phenylenediamine and the carboxy of cysteine. After the condensation reaction ,the surface of copolymer quantum dots riched in active amino and thiol groups. The $-\mathrm{NH}_{2}$ and $\mathrm{SH}$ on the surface of the O-Cys has strong affinity for $\mathrm{Hg}^{2+}$ to generate insoluble metal chelates, electron transfer occurs between the $-\mathrm{NH}_{2}$ and $-\mathrm{SH}$ on the surface of the O-Cys and $\mathrm{Hg}^{2+}$, resulting in fluorescence quenching.

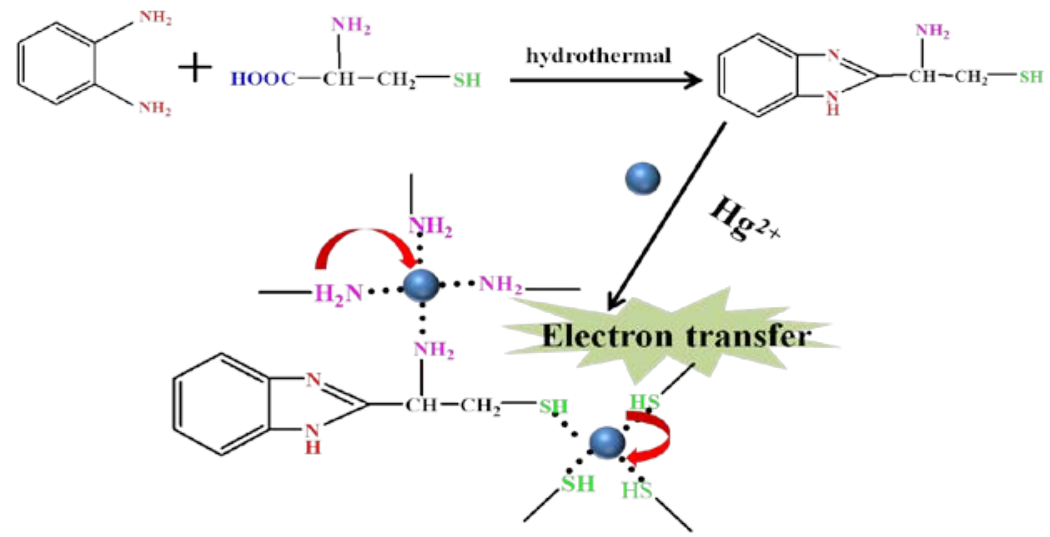

Scheme 1. A schematic diagram of the mechanism of O-Cys for $\mathrm{Hg}^{2+}$ detection.

\section{$2 \quad$ Materials and methods}

\section{$2.1 \quad$ Materials}

o-phenylenediamine (oPD), $\left(\mathrm{NH}_{4}\right)_{2} \mathrm{~S}_{2} \mathrm{O}_{8}$ (APS), L-cysteine (L-Cys), $\mathrm{NaCl}, \mathrm{KCl}, \mathrm{MgCl}_{2}, \mathrm{CaCl}_{2}, \mathrm{NiCl}_{2} \cdot 6 \mathrm{H}_{2} \mathrm{O}$, $\mathrm{HgCl}_{2}, \mathrm{AlCl}_{3}, \mathrm{Cd}\left(\mathrm{NO}_{3}\right)_{2}, \mathrm{~Pb}\left(\mathrm{NO}_{3}\right)_{2}, \mathrm{CuSO}_{4}, \mathrm{AgNO}_{3}, \mathrm{NiSO}_{4}, \mathrm{NaNO}_{2}, \mathrm{NiNO}_{3}, \mathrm{Co}\left(\mathrm{NO}_{3}\right)_{2}, \mathrm{Zn}\left(\mathrm{NO}_{3}\right)_{2}, \mathrm{KH}_{2} \mathrm{PO}_{4}$ and $\mathrm{Na}_{2} \mathrm{HPO}_{4}$ were purchased from kelong (chengdou,China) and used as received without further purification. The water used throughout all experiments was purified through a Millipore system.

\subsection{Synthesis of O-Cys}

Typically, $1.0 \mathrm{~mL}, 0.5 \mathrm{mM}$ Cys aqueous solution was added into 19mL, $50 \mathrm{mM}$ oPD aqueous solution, then $2 \mathrm{~mL}, 10 \mathrm{mM}$ APS aqueous solution was added to the above solution. The mixed solution was transferred into a $25 \mathrm{~mL}$ Teflon-lined autoclave and heated to $160{ }^{\circ} \mathrm{C}$ and maintained at that temperature for $72 \mathrm{~h}$ before being allowed to cool naturally to room temperature. The product was centrifuged to remove large 
dots and a yellow transparent supernate solution. The black precipitates were wasted with water by centrifugation twice, and the resulting precipitate are dried at $60^{\circ} \mathrm{C}$ for $12 \mathrm{~h}$ in vaccum for further use. The yield was about $71 \%$.

\subsection{Detection of $\mathbf{H g}^{2+}$}

First, we prepared the stock solution of $\mathrm{Hg}^{2+}$ with the concentration of $1 \times 10^{-9} \mathrm{M}$ at room temperature. In the experiment, a series of $\mathrm{Hg}^{2+}$ concentration were obtained by dilute stock solution. In brief, $2 \mathrm{ml}$ dots solution were added in 16 bottles, then numbered from 1 to 16 . Adding different vomule stock solution of $\mathrm{Hg}^{2+}$ from $0.2 \mathrm{ml}$ to $0.9 \mathrm{ml}$ to 16 bottles using pipette, then 16 bottles were constant volume to $10 \mathrm{ml}$ with distilled water. Mixing above solution separately, then measuring fluorescence spectrum after standing a few minutes with an emission wavelength of $560 \mathrm{~nm}$ at $25^{\circ} \mathrm{C}$.

\subsection{Characterization methods}

Transmission electron microscopy (TEM) measurements were made on a H-8100 EM(Hitachi, Tokyo, Japan) operated at an accelerating voltage of $20 \mathrm{kV}$. UV-vis spectra were obtained on a UV-7502PC Spectropheotometer. Fourier transform infrared (FTIR) was performed on a thermo Scientific Nicolet 6700 Spectrometer and samples were dispersed in potassiumbromide. Fluorescent emission and excitation spectra were recorded on a FL0912 $\mu 000$ cary Eclipse at room temperature $\left(25^{\circ} \mathrm{C}\right)$ in aqueous solution. The stability of these products was determined via contrast the fluorescent emission intensity of products aqueous solution under different conservative time at room temperature $\left(25^{\circ} \mathrm{C}\right)$. The optical densities measured on the UV-vis spectrum were obtained on a UV-7502PC Spectrophotometer.

\subsection{The quantum yield $(\varphi)$ measurement}

Quantum yield $(\varphi)$ was calculated by the following equation:

$$
\varphi=\varphi_{R} \times \frac{I}{I_{R}} \times \frac{A_{R}}{A} \times \frac{\eta^{2}}{\eta_{R}^{2}}
$$

where $I$ represented the measured integrated emission intensity (emission wavelength of $560 \mathrm{~nm}$ ), $\eta$ was the refractive index of the solvent, $A$ was the optical density measured on a UV-vis spectrophotometer, which was limited to less than 0.1 . The subscript $R$ refers to the reference standard with a known $\varphi$ [38]. Absolute values were calculated using the standard reference sample that had a fixed and known fluorescence quantum yield value. Here, we chose RhB dissolved in ethanol solution, which $\varphi_{R}$ was 0.68 . In order to minimize reabsorption effects, absorbency was kept under 0.1 at the excitation wavelength in the $10 \mathrm{~mm}$ fluorescence cuvette.

\section{$3 \quad$ Results and discussion}

\subsection{Characterization of O-Cys}

The typical TEM images of O-Cys thus formed were shown in Fig. 1a. The corresponding size distribution of O-Cys was shown in Fig. 1b. It can be seen from the Fig. 1 b that the quantum dot size of O-Cys were in the range of $1 \mathrm{~nm}-4 \mathrm{~nm}$ and with an average diameter was approximately $1.9 \mathrm{~nm}$.

The UV-vis spectra and FT-IR spectrometer were carried out to investigate the structure properties of O-Cys. Fig. 1c showed the UV-vis absorption spectrum of O-Cys. It had two typical UV-vis absorption peaks at $\sim 450$ and $\sim 400 \mathrm{~nm}$, Respectively. The absorption peaks centered at approximately $450 \mathrm{~nm}$ and $\sim 400 \mathrm{~nm}$ can be assigned to the $\Pi-\Pi^{*}$ and $n-\Pi^{*}$ transition of the benzenoid rings $[39,40]$.

The FT-IR spectrum of O-Cys, mixture O-Cys and $\mathrm{Hg}^{2+}$ were shown in Fig. 1d. It is clear that the adsorption peaks at $3240 \mathrm{~cm}^{-1}$ corresponding to the N-H stretching mode, and implying the presence of secondary amino groups. The peaks at 2920 and $2850 \mathrm{~cm}^{-1}$ can be assigned to the $\mathrm{C}-\mathrm{H}$ stretching mode 
and $\mathrm{C}-\mathrm{H}$ out-of-plane bending mode. The peak at $2550-2580 \mathrm{~cm}^{-1}$ areas signed to $-\mathrm{SH}$ stretching mode . However the reaction between - $\mathrm{SH}$ and $\mathrm{Hg}^{2+}$ were happened, the absorption peak of the -SH was obviously decreased. The peaks at 1239 and $1370 \mathrm{~cm}^{-1}$ were associated with the C-N stretching in the benzenoid and quinoid imine units, aromatic $\mathrm{C}=\mathrm{N}$ heterocycles stretching vibrations are at1309-1650 $\mathrm{cm}^{-1}[41,42]$. All the above observations indicate the successful formation of O-Cys including $-\mathrm{SH}$.

An excitation-dependent emission of O-Cys was observed in Fig. 1e. When excitation $\left(\lambda_{\text {ex }}\right)$ wavelength was increased from 500 to $560 \mathrm{~nm}$, the PL intensity increased gradually. However, when $\lambda_{\text {ex }}$ was increased from 560 to $580 \mathrm{~nm}$, the PL intensity decreased gradually. This showed that with the increase of excitation wavelength, number of excited state molecules increased gradually, and in the largest excitation wavelength, number of excited state molecules were the most. So we chose 560nm as excitation wavelength of O-Cys. We also observed that the emission peak did not shift any more than a maximum red shift when $\lambda_{\text {ex }}$ was increased from 500 to $580 \mathrm{~nm}$, which showed the O-Cys have unified chromophores. The maximum emission peak was observed at $623 \mathrm{~nm}$ for an excitation of $560 \mathrm{~nm}$. Fig. If showed the fluorescence excitation and emission spectrum of O-Cys. It is obviously shown that the maximum $\lambda_{\mathrm{ex}}$ and emission $\left(\lambda_{\mathrm{em}}\right)$ wavelength of O-Cys are 560 and $623 \mathrm{~nm}$, respectively.
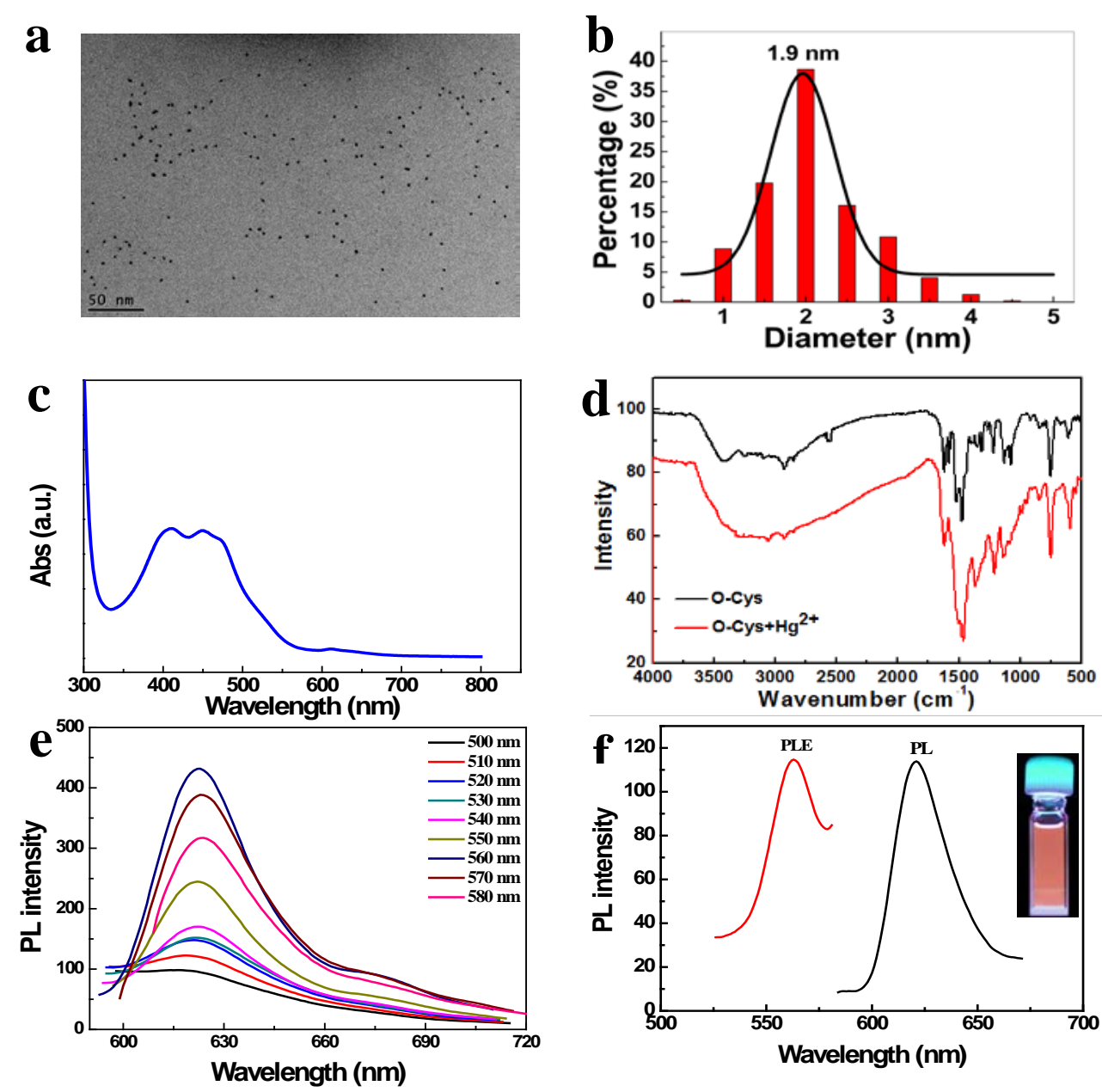

Fig. 1. (a) TEM images of O-Cys. (b) Corresponding size distribution of O-Cys. (c) Normalized UV-vis absorption of O-Cys. (d) The FT-IR spectrum of O-Cys, mixed solution of O-Cys and $\mathrm{Hg}^{2+}$. (e) PL spectrum of the O-Cys at different excitation wavelengths from 500 to $580 \mathrm{~nm}$; both the excitation and emission slit widths were $5 \mathrm{~nm}$. (f) Fluorescence excitation spectra and emission spectra of O-Cys aqueous solution at room temperature $\left(25^{\circ} \mathrm{C}\right)$. Inset: photographs of O-Cys aqueous solution. 


\subsection{Stability experiments}

The stability of product was very crucial for practical applications. Here, to confirm the stability of O-Cys, we observed the change of the PL intensities of O-Cys under different influencing factors such as continuous excitation under visible light and different $\mathrm{pH}$ values (Fig. 2). As shown in Fig. 2a, only a slight PL intensity change was observed, indicating high stability of the O-Cys after continuous excitation under visible light for more than a week. This also means the O-Cys were stable and had great potential applications. Meanwhile, in Fig. 2b, we also found the PL intensity was stable when the pH value was changed from 4 to 11. This meant that O-Cys had excellent stability and could be used in most biological environments.
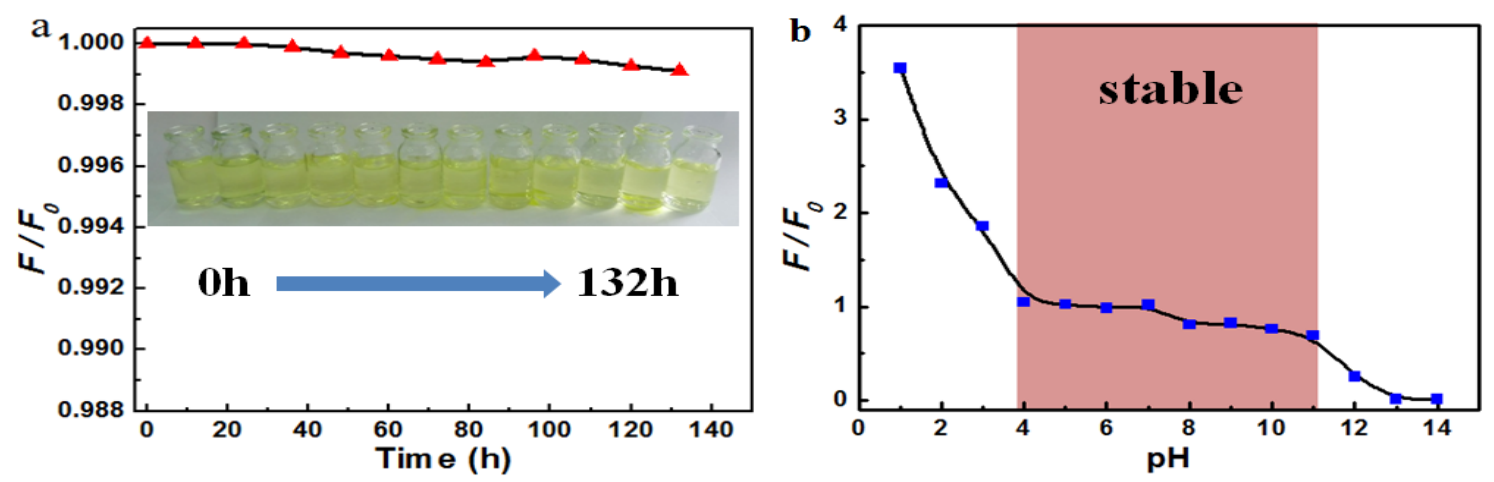

Fig. 2. (a) The PL intensity $\left(\lambda_{e x}=560 \mathrm{~nm}, \lambda_{e m}=623 \mathrm{~nm}\right)$ of the O-Cys in the different time under visible light. $F_{0}$ and $F$ are PL intensities in the initial $(\mathrm{t}=0)$ and specify time, respectively. Inset: the photograph of O-Cys in the different time under visible light. (b) The PL intensity $\left(\lambda_{e x}=560 \mathrm{~nm}, \lambda_{e m}=623 \mathrm{~nm}\right)$ of the O-Cys in the different $\mathrm{pH}$ at $25^{\circ} \mathrm{C}$ 。 $F_{0}$ and $F$ are PL intensities of O-Cys solution and specify $\mathrm{pH}$, respectively.

\subsection{Detection of $\mathrm{Hg}^{2+}$}

The stability of product was very crucial for practical applications. Here, to confirm the stability of O-Cys, we observed the change of the PL intensities of O-Cys under different influencing factors such as continuous excitation under visible light and different $\mathrm{pH}$ values (Fig. 2). As shown in Fig. 2a, only a slight $\mathrm{PL}$ intensity change was observed, indicating high stability of the O-Cys after continuous excitation under visible light for more than a week. This also means the O-Cys were stable and had great potential applications. Meanwhile, in Fig. 2b, we also found the PL intensity was stable when the pH value was changed from 4 to 11. This meant that O-Cys had excellent stability and could be used in most biological environments.

We further explored the feasibility of using the O-Cys for detection of $\mathrm{Hg}^{2+}$. For a sensitivity study, PL intensities change was monitored after adding different concentration $\mathrm{Hg}^{2+}$ to O-Cys solution for a fixed time of $10 \mathrm{~min}$. As the concentration of $\mathrm{Hg}^{2+}$ was increased from $2 \times 10^{-11}$ to $9 \times 10^{-11} \mathrm{M}$, the PL peak at 623 $\mathrm{nm}$ gradually decreased. It was obvious shown that $\mathrm{Hg}^{2+}$ could quench fluorescence of O-Cys. The reason of quenching was presumably via electron transfer. Strong coordination interactions between $\mathrm{Hg}^{2+}$ and the surface $-\mathrm{NH}_{2}$ and - $\mathrm{SH}$ groups of O-Cys resulted in the fluorescence quenching of O-Cys, which was the character of static quenching. Electron transfer could happen between $\mathrm{Hg}^{2+}$ and O-Cys. Furthermore, molecular orbital theory was adopted to interpret the quenching mechanism, schematically displayed in Scheme 2. As seen, when O-Cys accepted the energy without the existence of $\mathrm{Hg}^{2+}$ and the electron of O-Cys would be excited from the ground state (valence band) to the excited state (conduction band). And the excited electron was not stable, and could return to the ground state. In the returning process, O-Cys could emit fluorescence (Scheme 2 (a)). On the other hand, with the existence of $\mathrm{Hg}^{2+}$, the $-\mathrm{NH}_{2}$ and $-\mathrm{SH}$ on the surface of the O-Cys had strong affinity for $\mathrm{Hg}^{2+}$. The strong interaction force would lead to electron transfer between O-Cys and $\mathrm{Hg}^{2+}$, so the excited electron could directly jump into the LUMO level layer of the complex. The energy level of the complex was higher than that of O-Cys, so the excited electrons of O-Cys could return back to the ground state without emitting fluorescence, which would lead to the fluorescence quenching of O-Cys (Scheme 2 (b)). The PL intensity of the O-Cys was proportionately decreased upon increasing $\mathrm{Hg}^{2+}$ concentration, which could be observed in Fig. 3a. The fluorescence 
quenching data followed the Stern-Volmer equation, via either a dynamic or a static mechanism:

$$
F_{0} / F_{-1}=K_{S V} C
$$

where $\mathrm{K}_{\mathrm{sv}}$ is the Stern-Volmer quenching constant, c is the analyte $\left(\mathrm{Hg}^{2+}\right)$ concentration, and $\mathrm{F}_{0}, \mathrm{~F}$ are $\mathrm{PL}$ intensities of $\mathrm{O}-\mathrm{Cys}$ at $560 \mathrm{~nm}$ in the absence and presence of $\mathrm{Hg}^{2+}$, respectively. A linear Stern-Volmer equation in the concentration range of $2 \times 10^{-11}$ to $4 \times 10^{-11} \mathrm{M}$ was shown in Fig. 3b. The correlation coefficients $\left(\mathrm{R}^{2}\right)$ were 0.9967 . The limit of detection (LOD) for $\mathrm{Hg}^{2+}$, at a signal-to-noise ratio of 3, was estimated to be $1 \times 10^{-11} \mathrm{M}$, which was much lower than the maximum contamination level of $\mathrm{Hg}^{2+}$ in drinking water permitted by WHO $(30 \mathrm{nM})$ and the limit of the $10 \mathrm{nM}$ set by the U.S. EPA. The sensor provided a sensitivity and low LOD for $\mathrm{Hg}^{2+}$ that were much better than those previous reported. The method and fluorescent material of detection of $\mathrm{Hg}^{2+}$ by other fluorescent probes were shown in Table 1 [2,43-47] and Table 2 [1,3-4,10-12,48-53]. The as-prepared O-Cys had higher LOD, which could be indeed used as impressible fluorescent probes for separately $\mathrm{Hg}^{2+}$ with a high degree of accuracy and simplicity.

Table 1. Comparison of different detection method for monitoring $\mathrm{Hg}^{2+}$

\begin{tabular}{lcc}
\hline Detection method & Detection limit & Ref. \\
\hline Ratiometric Fluorescence & $5 \times 10^{-8} \mathrm{M}$ & {$[2]$} \\
ICP-AES & $3.5 \times 10^{-9} \mathrm{M}$ & {$[43]$} \\
Energy Transfer & $1.0 \times 10^{-10} \mathrm{M}$ & {$[44]$} \\
Photocatalytic & $2.5 \times 10^{-7} \mathrm{M}$ & {$[45]$} \\
FRET-Based Ratiometric Detection & $1.0 \times 10^{-7} \mathrm{M}$ & {$[46]$} \\
AAS/sequential injection & $4.5 \times 10^{-8} \mathrm{M}$ & {$[47]$} \\
\hline
\end{tabular}

Table 2. Comparison of different fluorescent material for $\mathrm{Hg}^{2+}$ detection.

\begin{tabular}{lcc}
\hline Fluorescent material & Detection limit & Ref. \\
\hline DNA-Capped Mesoporous Silica Nanoparticles & $2 \times 10^{-8} \mathrm{M}$ & {$[1]$} \\
Silver Amalgamation & $2.6 \times 10^{-9} \mathrm{M}$ & {$[3]$} \\
Lysine-Promoted Colorimetric Response of Gold Nanoparticles & $1 \times 10^{-8} \mathrm{M}$ & {$[4]$} \\
$\beta-C y c l o d e x t r i n$ & $2 \times 10^{-9} \mathrm{M}$ & {$[10]$} \\
$\mathrm{T}-\mathrm{Hg}^{2+}-\mathrm{T} /$ AuNPs & $5 \times 10^{-8} \mathrm{M}$ & {$[11]$} \\
Graphene Aptasensor & $5 \times 10^{-5} \mathrm{M}$ & {$[12]$} \\
Gold Nanorods & $1.5 \times 10^{-11} \mathrm{M}$ & {$[48]$} \\
Ammonium Group-Capped Gold Nanoparticles & $3 \times 10^{-8} \mathrm{M}$ & {$[49]$} \\
DNA-Functionalized Monolithic Hydrogels & $5 \times 10^{-9} \mathrm{M}$ & {$[50]$} \\
Silver Nanoparticle-Embedded Polymer & $1.7 \times 10^{-9} \mathrm{M}$ & {$[51]$} \\
Functionalized Carbon Nanodots & $5 \times 10^{-8} \mathrm{M}$ & {$[52]$} \\
Graphene Quantum Dots & $1.2 \times 10^{-7} \mathrm{M}$ & {$[53]$} \\
O-Cys & $1 \times 10^{-11} \mathrm{M}$ & This work \\
\hline
\end{tabular}

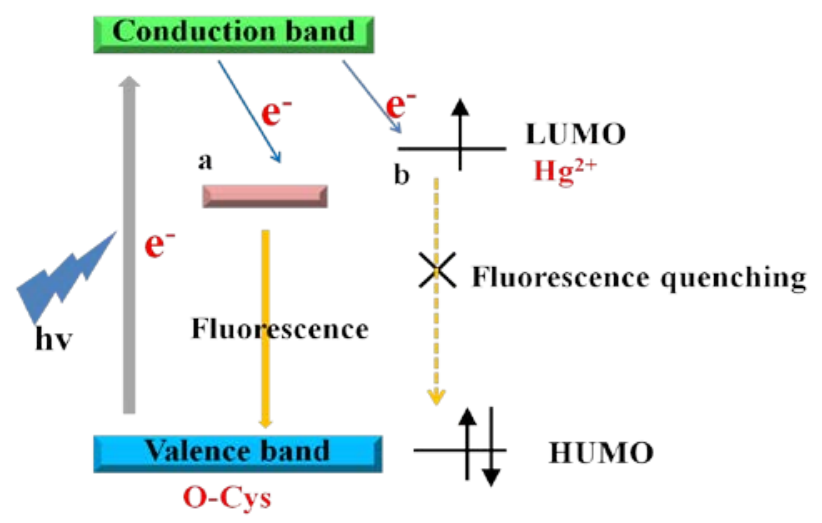

Scheme 2. Schematic for the fluorescence quenching mechanism according to molecular orbital theory in the absence (a) and presence (b) of $\mathrm{Hg}^{2+}$. 

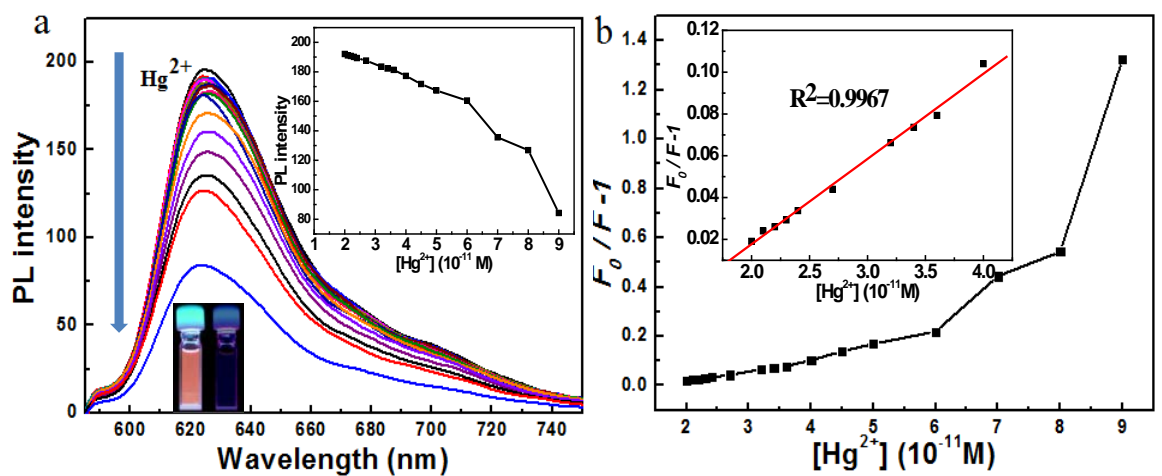

Fig. 3. (a) PL spectra of O-Cys in the presence of different concentrations of $\mathrm{Hg}^{2+}\left(2 \times 10^{-11} \mathrm{M}\right.$ to $\left.9 \times 10^{-11} \mathrm{M}\right)$ with an emission wavelength of $623 \mathrm{~nm}$ at $25^{\circ} \mathrm{C}$. Inset: The intensity of PL peak at excitation wavelength $560 \mathrm{~nm}$ in the presence of different concentrations of $\mathrm{Hg}^{2+}\left(2 \times 10^{-11} \mathrm{M}\right.$ to $\left.9 \times 10^{-11} \mathrm{M}\right)$ and photographs of O-Cys aqueous solution in the absence (left) and presence (right) of $\mathrm{Hg}^{2+}$. (b) The Stern-Volmer plot of the PL peak at emission wavelength of $623 \mathrm{~nm}$ in the presence of different concentrations of $\mathrm{Hg}^{2+}$. Inset: Linear fitting of the Stern-Volmer plot of the PL peak at $623 \mathrm{~nm}$ in the presence of different concentrations of $\mathrm{Hg}^{2+}\left(2 \times 10^{-11} \mathrm{M}\right.$ to $\left.4 \times 10^{-11} \mathrm{M}\right) . F_{0}, \quad F$ are PL intensities of O-Cys in the absence of $\mathrm{Hg}^{2+}$ and in the presence of different $\mathrm{Hg}^{2+}$ concentration, respectively.

Further, to confirm O-Cys can strongly interact with $\mathrm{Hg}^{2+}$, we considered that the change of PL intensity of the O-Cys in the presence of $\mathrm{Hg}^{2+}$ in Fig. 4. It was seen that the O-Cys solution in the absence of $\mathrm{Hg}^{2+}$ exhibited a strong PL peak at $623 \mathrm{~nm}$ (Fig. 4a, black curve). In contrast, the PL intensity of O-Cys obviously decreased in the presence of $\mathrm{Hg}^{2+}$, indicating that $\mathrm{Hg}^{2+}$ could effectively quench the PL of O-Cys (Fig. 4a, red curve). The most probable explanation for the quenching of PL of O-Cys in the presence of $\mathrm{Hg}^{2+}$ was based on the electron transfer mechanism. That is, $\mathrm{Hg}^{2+}$ is an acid of borderline hardness (according to the hard and soft acids and bases principle) and had strong affinity for sulfur donor atoms than the nitrogen atom, as result of forming the stable metal complexes[42]. Morever, when adding a strong $\mathrm{Hg}^{2+}$ chelator (such as EDTA), $\mathrm{Hg}^{2+}$ were removed from the surface of O-Cys by forming metal chelates with EDTA, which resulted in the PL recovery of O-Cys (Fig. 4a, blue line). As increasing EDTA concentration, the PL peak of O-Cys at $623 \mathrm{~nm}$ gradually increased were observed in Fig. 4b.
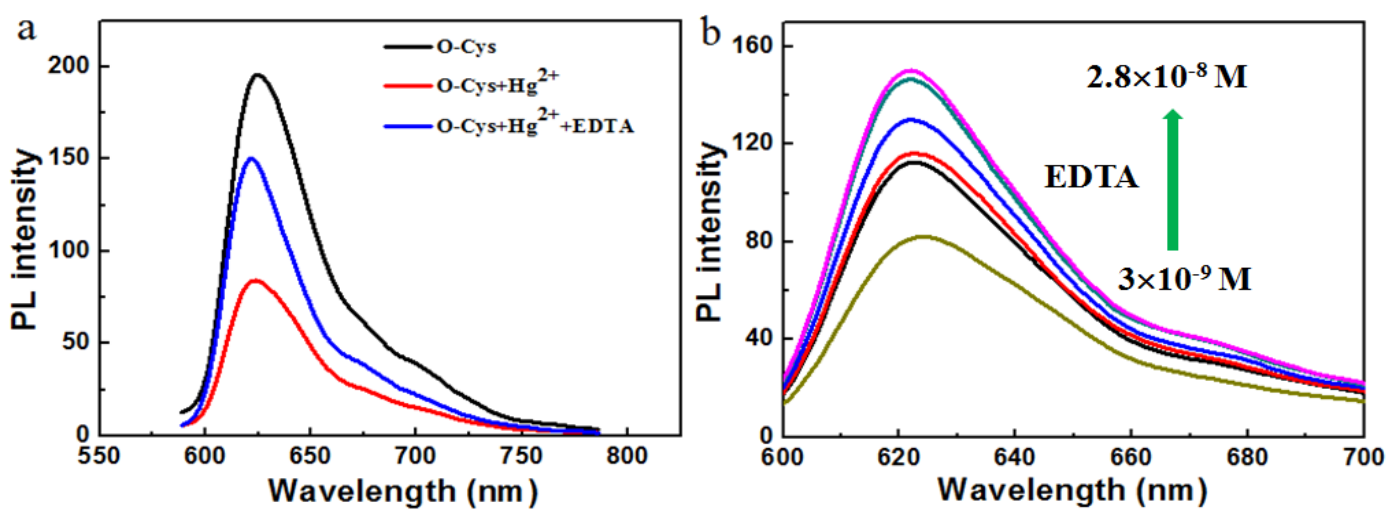

Fig. 4. (a) The PL spectra of O-Cys (black line), O-Cys and $\mathrm{Hg}^{2+}$ (concentration of $\mathrm{Hg}^{2+}$ was $9 \times 10^{-11} \mathrm{M}$, red line), mixture of O-Cys, $\mathrm{Hg}^{2+}$ and EDTA (concentration of $\mathrm{Hg}^{2+}$ was $9 \times 10^{-11} \mathrm{M}$, concentration of EDTA was $2.8 \times 10^{-8} \mathrm{M}$, blue line). (b) PL emission spectrum $\left(\lambda_{e x}=560 \mathrm{~nm}\right)$ of $\mathrm{O}$-Cys in the presence of $\mathrm{Hg}^{2+}\left(9 \times 10^{-11} \mathrm{M}\right)$ with different concentrations of EDTA $\left(3 \times 10^{-9}-2.8 \times 10^{-8} \mathrm{M}\right)$ at $25^{\circ} \mathrm{C}$.

To confirm our suspect that $\mathrm{Hg}^{2+}$ had higher fluorescent quenching ability for as-prepared O-Cys was due to $-\mathrm{NH}_{2}$ and $-\mathrm{SH}$ work together, we synthesized other two kind of polymer containing $-\mathrm{NH}_{2}$ and in the 
absent of - $\mathrm{SH}$ via the same method, one was poly(o-phenylenediamine) (PoPD), other was o-phenylenediamine-cystine copolymer (ocyCP). A schematic diagram of the structure of PoPD and ocyCP were shown in Scheme 3. It is obviously shown that PoPD and ocyCP for the detection ability of $\mathrm{Hg}^{2+}$ were worse than O-Cys with detection limit $1.0 \times 10^{-11} \mathrm{M}$ (Fig. 5.). The detection limits for $\mathrm{Hg}^{2+}$ were $1.0 \times 10^{-7}$ and $2.0 \times 10^{-7}$, respectively. These results further confirmed that $-\mathrm{NH}_{2}$ and $-\mathrm{SH}$ work together in the detection of mercury ion, most important, these results also confirmed the $-\mathrm{SH}$ enhance detection ability of $\mathrm{O}-\mathrm{Cys}$ for $\mathrm{Hg}^{2+}$.<smiles>Nc1cc2nc3cc4nc5ccccc5nc4cc3nc2cc1N</smiles>

B

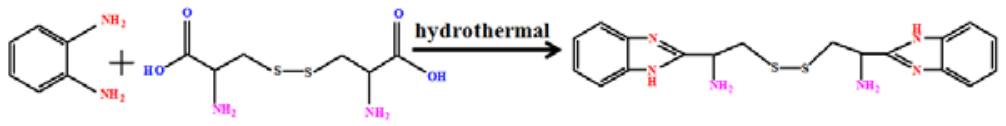

Scheme 3. A schematic diagram of the structure of PoPD and ocyCP.
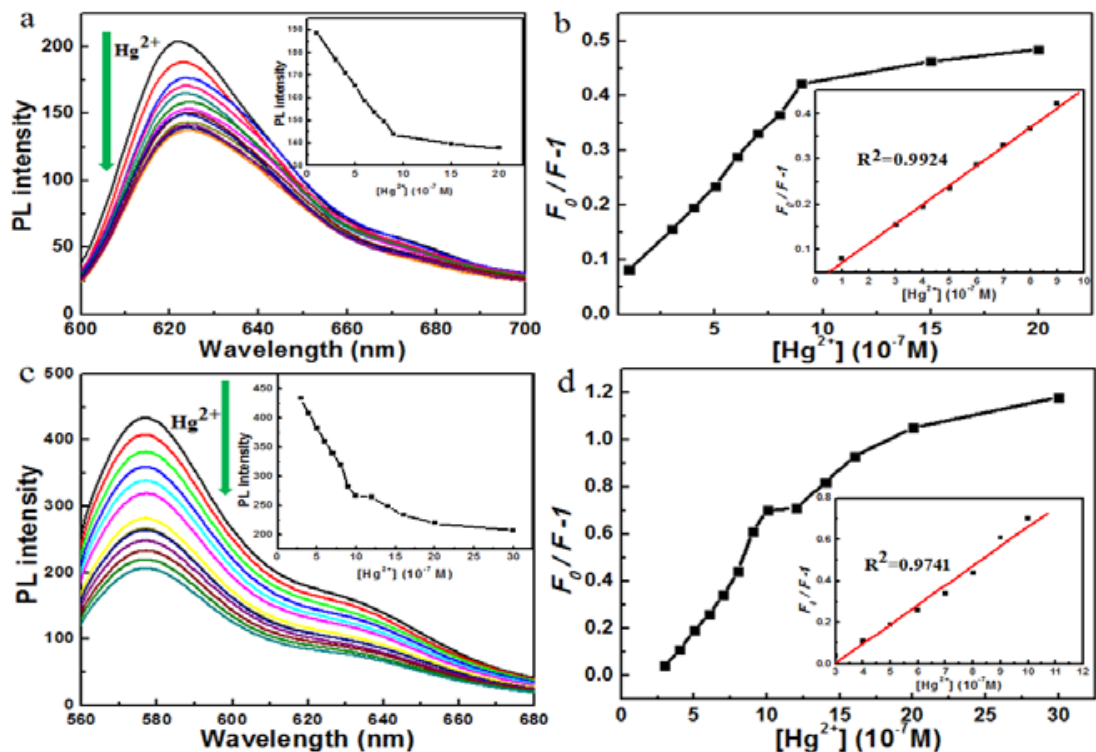

Fig. 5. (a) PL emission spectrum $\left(\lambda_{e x}=560 \mathrm{~nm}, \lambda_{e m}=623 \mathrm{~nm}\right)$ of PoPD in the presence of $\mathrm{Hg}^{2+}$ with different concentrations $\left(1 \times 10^{-7} \mathrm{M}-2 \times 10^{-6} \mathrm{M}\right)$ at $25{ }^{\circ} \mathrm{C}$. Inset: the intensity of PL peak at excitation wavelength $560 \mathrm{~nm}$ in the presence of different concentrations $\mathrm{Hg}^{2+}\left(1 \times 10^{-7} \mathrm{M}-2 \times 10^{-6} \mathrm{M}\right)$. (b) The Stern-Volmer plot of the PL peak at emission wavelength of $623 \mathrm{~nm}$ in the presence of different concentrations of $\mathrm{Hg}^{2+} . \mathrm{F}_{0}$ and $\mathrm{F}$ are PL intensities of PoPD without and with the presence of $\mathrm{Hg}^{2+}\left(1 \times 10^{-7} \mathrm{M}-2 \times 10^{-6} \mathrm{M}\right)$ at $25^{\circ} \mathrm{C}$, respectively. Inset: linear fitting of the Stern-Volmer plot of the PL peak at $623 \mathrm{~nm}$ in the presence of different concentrations of $\mathrm{Hg}^{2+} \operatorname{ion}\left(1 \times 10^{-7} \mathrm{M}-9 \times 10^{-7} \mathrm{M}\right)$. (c) PL emission spectrum $\left(\lambda_{e x}=530 \mathrm{~nm}, \lambda_{e m}=577 \mathrm{~nm}\right)$ of ocyCP in the presence of $\mathrm{Hg}^{2+}$ ions with different concentrations $\left(3 \times 10^{-7}\right.$ $\mathrm{M}-3 \times 10^{-6} \mathrm{M}$ ) at $25^{\circ} \mathrm{C}$. Inset: the intensity of PL peak at excitation wavelength $530 \mathrm{~nm}$ in the presence of different concentrations $\mathrm{Hg}^{2+}\left(3 \times 10^{-7} \mathrm{M}-3 \times 10^{-6} \mathrm{M}\right)$. (d) The Stern-Volmer plot of the PL peak in the presence of different concentrations of $\mathrm{Hg}^{2+}$ ions. $\mathrm{F}_{0}$ and $\mathrm{F}$ are $\mathrm{PL}$ intensities of ocyCP without and with the presence of $\mathrm{Hg}^{2+}\left(3 \times 10^{-7}\right.$ $\left.\mathrm{M}-3 \times 10^{-6} \mathrm{M}\right)$ at $25^{\circ} \mathrm{C}$, respectively. Inset: linear fitting of the Stern-Volmer plot of the PL peak at $577 \mathrm{~nm}$ in the presence of different concentrations of $\mathrm{Hg}^{2+}\left(3 \times 10^{-7} \mathrm{M}-1 \times 10^{-6} \mathrm{M}\right)$.

\subsection{Selectivity experiments}

As fluorescence probe, in addition to its high sensitivity, selectivity was alao another important parameter 
to evaluate the performance of the sensing system. Under the experiment optimal conditions, we tested the $\mathrm{PL}$ intensity changes of the $\mathrm{O}-\mathrm{Cys}$ in the presence of competitive metal ions and other ions under the same conditions, respectively, including $\mathrm{Na}^{+}, \mathrm{K}^{+}, \mathrm{Mg}^{2+}, \mathrm{Ca}^{2+}, \mathrm{Al}^{3+}, \mathrm{Cu}^{2+}, \mathrm{Hg}^{2+}, \mathrm{Cd}^{2+}, \mathrm{Pb}^{2+}, \mathrm{Ni}^{2+}, \mathrm{Co}^{2+}, \mathrm{Zn}^{2+}, \mathrm{Cl}^{-}$, $\mathrm{SO}_{4}{ }^{2-}, \mathrm{NO}_{3}^{-}, \mathrm{NO}_{2}^{-}, \mathrm{H}_{2} \mathrm{PO}_{4}^{-}, \mathrm{HPO}_{4}{ }^{2-}$, and as shown in Fig. 6. The PL intensities of the O-Cys with and without the present of other ions were denoted by $\mathrm{F}$ and $\mathrm{F}_{0}$, respectively. It was obviously seen that a much higher PL intensity respond was observed for O-Cys upon addition of $\mathrm{Hg}^{2+}$. In contrast, no tremendous decrease was observed by adding other ions into the O-Cys solution. All these results suggested that as-prepared O-Cys showed excellent selectivity and sensitivity for $\mathrm{Hg}^{2+}$ ion in biological and water environmental fields, which had high practical applications.

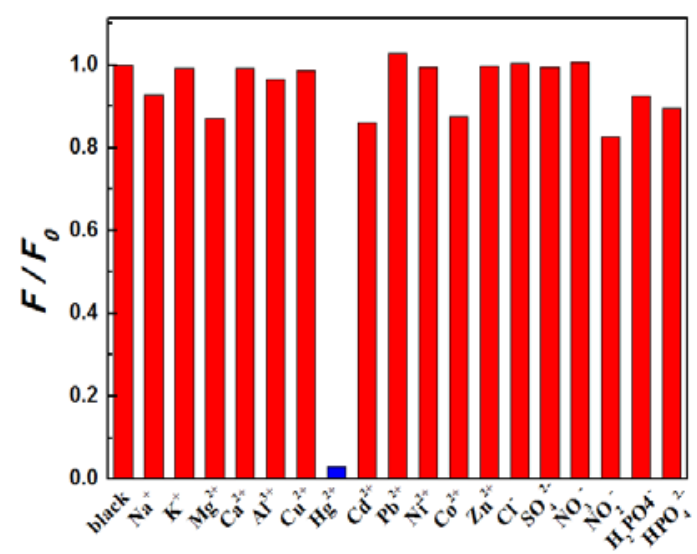

Fig. 6. Fluorescence response of $\mathrm{O}-\mathrm{Cys}$ in the presence of different ions at $25^{\circ} \mathrm{C} \cdot \mathrm{F}_{0}$ and $\mathrm{F}$ are $\mathrm{PL}$ intensities $\mathrm{O}-\mathrm{Cys}$ without and with the presence of other ions. The concentrations of all ions is $5 \times 10^{-5} \mathrm{M}$. The ions are black, $\mathrm{Na}^{+}, \mathrm{K}^{+}$, $\mathrm{Mg}^{2+}, \mathrm{Ca}^{2+}, \mathrm{Al}^{3+}, \mathrm{Cu}^{2+}, \mathrm{Hg}^{2+}, \mathrm{Cd}^{2+}, \mathrm{Pb}^{2+}, \mathrm{Ni}^{2+}, \mathrm{Co}^{2+}, \mathrm{Zn}^{2+}, \mathrm{Cl}^{-}, \mathrm{SO}_{4}^{2-}, \mathrm{NO}_{3}^{-}, \mathrm{NO}_{2}^{-}, \mathrm{H}_{2} \mathrm{PO}_{4}^{-}, \mathrm{HPO}_{4}{ }^{2-}$.

\section{Conclusions}

In summary, low-cost, high-stability fluorescent O-Cys was synthesized by a facile and one step hydrothermal method. The O-Cys could be used as a sensitive fluorescent probe for the detection of $\mathrm{Hg}^{2+}$ with detection limit of $1 \times 10^{-11} \mathrm{M}$, which was superior to most current methods and fluorescent materials for $\mathrm{Hg}^{2+}$ analysis. On the other hand, we also discussed the working mechanism of $\mathrm{Hg}^{2+}$ detection. We found $-\mathrm{SH}$ in the O-Cys can largely enhance the ability of $\mathrm{Hg}^{2+}$ detection compared with polymer without - $\mathrm{SH}$, which were $\mathrm{PoPD}$ and ocyCP, respectively. The $\mathrm{O}-\mathrm{Cys}$ was comparatively stable in a wide range of $\mathrm{pH}$ values and continuous illumination, which meaned it could be applied in gentle condition. The fluorescent O-Cys provided a good exponent of detection $\mathrm{Hg}^{2+}$ with low detection limit. We supposed that the O-Cys will have many potential applications in environmental detection and health care.

\section{References}

1. Y. F. Zhang, Q. Yuan, T. Chen, X. B. Zhang, Y. Chen, W. H. Tan, "DNA-Capped Mesoporous Silica Nanoparticles as an Ion-Responsive Release System to Determine the Presence of Mercury in Aqueous Solutions," Anal. Chem. , vol. 84, no. 4, pp. 1956-1962, 2012.

2. E. S. Childress, C. A. Roberts, D. Y. Sherwood, C. L. M. LeGuyader, E. J. Harbron, "Ratiometric Fluorescence Detection of Mercury Ions in Water by Conjugated Polymer Nanoparticles," Anal. Chem., vol. 84, no. 3, pp. 1235-1239, 2012.

3. L. Deng, X. Y. Ouyang, J. Y. Jin, C. Ma, Y. Jiang, J. Zheng, J. S. Li, Y. H. Li, W. H. Tan, R. H. Yang, "Exploiting the Higher Specificity of Silver Amalgamation: Selective Detection of Mercury(II) by Forming Ag/Hg Amalgam," Anal. Chem., vol. 85, no. 18, pp. 8594-8600, 2013. 
4. G. Sener, L. Uzun, A. Denizli, "Lysine-Promoted Colorimetric Response of Gold Nanoparticles: A Simple Assay for Ultrasensitive Mercury(II) Detection," Anal. Chem., vol. 86, no. 1, pp. 514-520, 2014.

5. W. B. Lu, X. Y. Qin, S. Liu, G. H. Chang, Y. W. Zhang, Y. L. Luo, A. M. Asiri, A. O. Al-Youbi, X. P.Sun, "Economical, Green Synthesis of Fluorescent Carbon Nanoparticles and Their Use as Probes for Sensitive and Selective Detection of Mercury(II) Ions," Anal. Chem., vol. 84, no. 12, pp. 5351-5357, 2012.

6. D. G. He, X. X. He, K. M. Wang, Y. X. Zhao, Z. Zou, "Regenerable Multifunctional Mesoporous Silica Nanocomposites for Simultaneous Detection and Removal of Mercury(II), Langmuir," vol. 29, no. 19, pp. 5896-5904, 2013.

7. Y. C. Shih, C. Y. Ke, C. J. Yu, C. Y. Lu, W. L. Tseng, "Combined Tween 20-Stabilized Gold Nanoparticles and Reduced Graphite Oxide-Fe3O4 Nanoparticle Composites for Rapid and Efficient Removal of Mercury Species from a Complex Matrix," ACS Appl. Mater. Interfaces, vol. 6, no. 20, pp. 17437-17445, 2014.

8. J. Jung, J. C. Kim, Y. Rho, M. Kim, W. Kwon, H. Kim, M. Ree, "Molecular Layer-by-Layer Self-Assembly and Mercury Sensing Characteristics of Novel Brush Polymers Bearing Thymine Moieties," ACS Appl. Mater. Interfaces, vol. 3, no. 7, pp. 2655-2664, 2011.

9. W. B. Lu, X. Y. Qin, S. Liu, G. H. Chang, Y. W. Zhang, Y. L. Luo, A. M. Asiri, A. O. Al-Youbi, X. P. Sun, "Economical, Green Synthesis of Fluorescent Carbon Nanoparticles and Their Use as Probes for Sensitive and Selective Detection of Mercury(II) Ions," Anal. Chem., vol. 84, no. 12, pp. 5351-5357, 2012.

10. G. Fang, M. Y. Xu, F. Zeng, S. Z. Wu, " $\beta$-Cyclodextrin as the Vehicle for Forming Ratiometric Mercury Ion Sensor Usable in Aqueous Media, Biological Fluids," and Live Cells, Langmuir, vol. 26, no. 22, pp. 17764-17771, 2010.

11. G. H. Chen, W. Y. Chen, Y. C. Yen, C. W. Wang, H. T. Chang, C. Fu.Chen, "Detection of Mercury(II) Ions Using Colorimetric Gold Nanoparticles on Paper-Based Analytical Devices," Anal. Chem. , vol. 86, no. 14, pp. 6843-6849, 2014.

12. J. H. An, S. J. Park, O. S. Kwon, J. Bae, J. Jang, "High-Performance Flexible Graphene Aptasensor for Mercury Detection in Mussels, ACS Nano," vol. 7, no. 12, pp. 10563-10571, 2013.

13. Q. S. Wei, R. Nagi, K. Sadeghi, S. Feng, E. Yan, S. J. Ki, R. Caire,D. Tseng, A. Ozcan, "Detection and Spatial Mapping of Mercury Contamination in Water Samples Using a Smart-Phone," ACS Nano. , vol. 8, no. 2, pp. 11211129, 2014.

14. L. Zhang, H. X. Chang, A. Hirata, H. K. Wu, Qi. K. Xue, M. W. Chen, "Nanoporous Gold Based Optical Sensor for Sub-ppt Detection of Mercury Ions," ACS Nano., vol. 7, no. 5, pp. 4595-4600, 2013.

15. X. H. Li, Y. Q. Wu, Y. Liu, X. M. Zou, L. M. Yao, F. Y. Li ,W. Feng, "Cyclometallated ruthenium complex-modified upconversion nanophosphors for selective detection of $\mathrm{Hg} 2+$ ions in water," Nanoscale, vol. 6, no. 2, pp. 1020-1028, 2014.

16. W. F. Luo, H. E. Jiang, K. M. Zhang, W. Liu, X. L. Tang, W. Dou, Z. H. Ju, Z. Q. Li, W. S. Liu, "A reusable ratiometric two-photon chemodosimeter for $\mathrm{Hg} 2+$ detection based on ESIPT and its application in bioimaging," J. Mater. Chem. B, vol. 3, no. 17, pp. 3459-3464, 2015.

17. J. Q. Pan, Y. Z. Sheng, J. X. Zhang, J. M. Wei, P. Huang, X. Zhang, B. X. Feng, "Preparation of carbon quantum dots/TiO2 nanotubes composites and their visible light catalytic applications," J. Mater. Chem. A, vol. 2, no. 42 , pp. 18082-18086, 2014.

18. S. Mitra, S. Chandra, P. Patra, P. Pramanik, A, Goswami, "Novel fluorescent matrix embedded carbon quantum dots for the production of stable gold and silver hydrosols," J. Mater. Chem. , vol. 2, pp. 17638-17641, 2011.

19. G. S. Kumar, R. Roy, D. Sen, U. K. Ghorai, R. Thapa, N. Mazumder, S. Saha, K. K. Chattopadhyay, "Amino-functionalized graphene quantum dots: origin of tunable heterogeneous photoluminescence," Nanoscale, vol. 6, no. 6, pp. 18082-18086, 2014.

20. I. Yildiz, M. Tomasulo, F. M. Raymo, "Electron and energy transfer mechanisms to switch the luminescence of semiconductor quantum dots," J. Mater. Chem., vol. 18, no. 46, pp. 5577-5584, 2008.

21. Y. H. Chan, F. M. Ye, M. E. Gallina, X. J. Zhang, Y. H. Jin, I. C. Wu, D. T. Chiu, "Hybrid Semiconducting Polymer Dot-Quantum Dot with Narrow-Band Emission, Near-Infrared Fluorescence, and High Brightness," J. Am. Chem. Soc., vol. 134, no. 17, pp. 7309-7312, 2012.

22. C. Wu, B. Bull, C. Szymanski, K.Christensen, J. McNeill, " Multicolor Conjugated Polymer Dots for Biological Fluorescence Imaging," ACS Nano., vol. 2, no. 11, pp. 2415-2423, 2008.

23. F. M. Ye, C. F. Wu, Y. H. Jin, M. Wang, Y. H. Chan, J. B. Yu,W. Sun, S. Hayden, D. T. Chiu, " A compact and highly fluorescent orange-emitting polymer dot for specific subcellular imagingw," Chem. Commun. , vol. 48, no. 12, pp. 1778-1780, 2012. 
24. P. J. Wu, S. Y. Kuo, Y. C. Huang, C. P. Chen, Y. H. Chan, " Polydiacetylene-Enclosed Near-Infrared Fluorescent Semiconducting Polymer Dots for Bioimaging and SensingAnal," Chem. , vol. 86, no. 10, pp. 4831-4839, 2014.

25. D. Tuncel, H. V. Demir, "Conjugated polymer nanoparticles are highly versatile nano-structured materials that can potentially find applications in various areas such as optoelectronics, photonics, bio-imaging, bio-sensing and nanomedicine," Nanoscale, vol. 2, no. 4, pp. 484-494, 2010.

26. C. F. Wu, S. J. Hansen, Q. Hou, J. B.Yu, M. Zeigler, Y. H. Jin, D. R. Burnham, J. D. McNeill, J. M. Olson, D. T. Chiu, " Design of Highly Emissive Polymer Dot Bioconjugates for In Vivo Tumor Targeting," Angew. Chem. Int. Ed. , vol. 50, no. 15, pp. 3430-3434, 2011.

27. K. Sun, H. B. Chen, L. Wang, S. Y. Yin, H. Y. Wang, G. X. Xu, D. N. Chen, X. J. Zhang, C. F. Wu, W. P. Qin, "Size-Dependent Property and Cell Labeling of Semiconducting Polymer Dots," ACS Appl. Mater. Interfaces, vol. 6, no. 13, pp. 10802-10812, 2014.

28. Y. Rong, C. F. Wu, J. B.Yu, X. J. Zhang, F. M. Ye, M. Zeigler, M. E. Gallina, I. C. Wu,Y. Zhang, Y. H. Chan, W. Sun, K. Uvdal, D. T. Chiu, " Multicolor Fluorescent Semiconducting Polymer Dots with Narrow Emissions and High Brightness," ACS Nano., vol. 7, no. 1, pp. 376-384, 2013.

29. X. J. Zhang, J. B. Yu, C. F. Wu, Y. H. Jin, Y. Rong, F. M. Ye, D. T. Chiu, "Importance of Having Low-Density Functional Groups for Generating High-Performance Semiconducting Polymer Dots," ACS Nano., vol. 6, no. 6, pp. 5429-5439, 2012.

30. F. Ye, C. Wu, Y. Jin, M. Wang, Y. H. Chan, J. Yu, W. Sun, S. Hayden and D. T. Chiu, " A compact and highly fluorescent orange-emitting polymer dot for specific subcellular imaging," Chem. Commun., vol. 48, no. 12, pp. 1778-1780, 2012.

31. Y. Zhang, J. B. Yu, M. E. Gallina, W. Sun, Y. Rong. D. T. Chiu, " Highly luminescent, fluorinated semiconducting polymer dots for cellular imaging and analysis," Chem. Commun., vol. 49, no. 74, pp. 8256-8258, 2013.

32. Y. H. Chan, Y. H. Jin, C. F. Wu, D. T. Chiu, " Copper(II) and iron(II) ion sensing with semiconducting polymer dots," Chem. Commun., vol. 47, no. 10, pp. 2820-2822, 2011.

33. L. Chai; Q. Li; Y. Zhu; Z. Zhang; Q. Wang; Y. Wang; Z. Yang, "Synthesis of thiol-functionalized spent grain as a novel adsorbent for divalent metal ions," Bioresour. Technol. , vol. 101, pp. 6269-6272, 2010.

34. S. Wang, M. H. Wei, Y.M. Huang, "Biosorption of Multifold Toxic Heavy Metal Ions from Aqueous Water onto Food Residue Eggshell Membrane Functionalized with Ammonium Thioglycolate," J. Agric. Food Chem. , vol. 61, no. 21, pp. 4988-4996, 2013.

35. G. Li; Z. Zhao; J. Liu; G. Jiang, " Effective heavy metal removal from aqueous systems by thiol functionalized magnetic mesoporous silica," J. Hazard. Mater. , vol. 192, no. 1, pp. 277-283, 2011.

36. Y. Rao, B. Xiang, E. Bramanti, A. D'Ulivo, Z. Mester, "Determination of Thiols in Yeast by HPLC Coupled with LTQ-Orbitrap Mass Spectrometry after Derivatization with p-(Hydroxymercuri)benzoate," J. Agric. Food Chem. , vol. 58, no. 3, pp. 1462-1468, 2010.

37. H. Pesonen, R. Aksela, K.Laasonen, " Density Functional Complexation Study of Metal Ions with Cysteine," J. Phys. Chem. A, vol. 114, no. 1, pp. 466-473, 2010.

38. H. Huang, C. G. Li, S. J. Zhu, H. L. Wang, C. L. Chen, Z. R. Wang, T. Y. Bai, Z. Shi, S. H. Feng, "Histidine-Derived Nontoxic Nitrogen-Doped Carbon Dots for Sensing and Bioimaging Applications," Langmuir, vol. 30, no. 45, pp. 13542-13548, 2014.

39. H. Li, L. Wang, Y. Zhang, J. Tian, X. P. Sun, " Coordination Polymer Nanobelts as an Effective Sensing Platform for Fluorescence-enhanced Nucleic Acid DetectionMacromol," Rapid Commun. , vol. 32, no. 12, pp. 899-904, 2011.

40. H. Li, Y. Zhang, Y. Luo, X. P. Sun, " Nano-C60: A Novel, Effective, Fluorescent Sensing Platform for Biomolecular Detection," Small, vol. 7, no. 11, pp. 1562-1568, 2011.

41. H. L. Li, X. P. Sun, "Fluorescence-enhanced nucleic acid detection: using coordinationpolymer colloids as a sensing platform," Chem. Commun, vol. 47, no. 9, pp. 2625-2627, 2011.

42. Z. X. Wang, S. N. Ding, " One-Pot Green Synthesis of High Quantum Yield Oxygen-Doped, Nitrogen-Rich, Photoluminescent Polymer Carbon Nanoribbons as an Effective Fluorescent Sensing Platform for Sensitive and Selective Detection of Silver(I) and Mercury(II) Ions," Anal. Chem., vol. 86, no. 15, pp. 7436-7445, 2014.

43. Z. L.Zhu, G. C .Chan, S. J. Ray, X. R. Zhang, G. M. Hieftje, "Use of a Solution Cathode Glow Discharge for Cold Vapor Generation of Mercury with Determination by ICP-Atomic Emission Spectrometry," Anal. Chem. , vol. 80, no. 18, pp. 7043-7050, 2008.

44. K. Y. Pu, Z. T. Luo, K. Li, J. P. Xie, B. Liu, " Energy Transfer between Conjugated-Oligoelectrolyte-Substituted POSS and Gold Nanocluster for Multicolor Intracellular Detection of Mercury Ion," J. Phys. Chem. C, vol. 115, no. 26, pp. 13069-13075, 2011. 
45. E. Gkika, A . Troupis, A . Hiskia, E . Papaconstantinou, "Photocatalytic Reduction and Recovery of Mercury by Polyoxometalates," Environ. Sci. Technol., vol. 39, no. 11, pp. 4242-4248, 2005.

46. C. Ma, F. Zeng, L. F. Huang, S. Z. Wu, "FRET-Based Ratiometric Detection System for Mercury Ions in Water with Polymeric Particles as Scaffolds," J. Phys. Chem. B, vol. 115, no. 5, pp. 874-882, 2011.

47. H. Erxleben, J. Ruzicka, "Atomic Absorption Spectroscopy for Mercury, Automated by Sequential Injection and Miniaturized in Lab-on-Valve System," Anal. Chem., vol. 77, no. 16, pp. 5124-5128, 2005.

48. T. Placido, G.Aragay, J. Pons, R. Comparelli, M. Lucia Curri, A. Merkoc I, " Ion-Directed Assembly of Gold Nanorods: A Strategy for Mercury Detection," ACS Appl. Mater. Interfaces, vol. 5, no. 3, pp. 1084-1092, 2013.

49. D. B. Liu, W. S. Qu, W. W. Chen, W. Zhang, Z. Wang, X. Y. Jiang, " Highly Sensitive, Colorimetric Detection of Mercury(II) in Aqueous Media by Quaternary Ammonium Group-Capped Gold Nanoparticles at Room Temperature," Anal. Chem., vol. 82, no. 23, pp. 9606-9610, 2010.

50. K. A. Joseph, N. Dave, J. W. Liu, " Electrostatically Directed Visual Fluorescence Response of DNA-Functionalized Monolithic Hydrogels for Highly Sensitive Hg2+ Detection," ACS Appl. Mater. Interfaces, vol. 3, no. 3, pp. 733-739, 2011.

51. G. V. Ramesh,T. P. Radhakrishnan, "A Universal Sensor for Mercury (Hg, HgI, HgII) Based on Silver Nanoparticle-Embedded Polymer Thin Film," ACS Appl. Mater. Interfaces, vol. 3, no. 4, pp. 988-994, 2011.

52. C. Yuan, B. H. Liu, F. Liu, M. Y. Han, Z. P. Zhang, "Fluorescence "Turn On" Detection of Mercuric Ion Based on Bis(dithiocarbamato)copper(II) Complex Functionalized Carbon Nanodots," Anal. Chem., vol. 86, no. 2, pp. 1123-1130, 2014.

53. L. L. Li, G. H. Wu, T. Hong, Z. Y. Yin, D. Sun, E. S. Abdel-Halim, J. J. Zhu, " Graphene Quantum Dots as Fluorescence Probes for Turn-off Sensing of Melamine in the Presence of Hg2+," ACS Appl. Mater. Interfaces, vol. 6, no. 4, pp. 2858-2864, 2014. 